\title{
Effect of hot climate of Saudi Arabia on physical and mechanical properties of single use polypropylene packaging films
}

\author{
Aravinthan Gopanna, Ph.D. ${ }^{1}$ (D) Selvin P. Thomas, Ph.D. ${ }^{2}$ (D) Krishna Prasad Rajan, Ph.D. ${ }^{2}$ (D) ${ }^{a}$ \\ ${ }^{1}$ Chemical Skills Department, Yanbu Technical Institute, ${ }^{2}$ Department of Chemical Engineering Technology, Yanbu Industrial College \\ Keywords: Weathering studies, Disposable plastic films, Morphology, Flammability, Spectroscopy, Thermal analysis \\ https://doi.org/10.53370/001c.29581
}

\section{Yanbu Journal of Engineering and Science}

Vol. 18, Issue 1, 2021

\begin{abstract}
Two types of single use plastic films were used to study the effect of hot climate conditions of Saudi Arabia during a six-month experiment. The objective of the study is to understand the degradation behavior of the single use packaging films under direct sunlight exposure with variation in humidity. The films were kept on a specially designed experimental setup. The films were analyzed every month with respect to morphology, spectroscopy, thermal and mechanical properties. The microscopic images showed initiation of cracks on the exterior of films. Mechanical properties such as tensile strength and tensile modulus were measured and a decrease of 17 and $7 \%$ from the virgin material was noticed. The thermal and flammability properties also showed a decrease which confirmed the ageing of the films due to the climatic conditions. The water contact angle showed 20\% decrease which indicated the effect of the weathering conditions to make the films less hydrophobic. The degraded packaging films after the exposure could be used as recycling component for the preparation of reusable single use plastic compounds.
\end{abstract}

\section{INTRODUCTION}

Due to their versatile nature, plastics are becoming the essential ingredients to provide quality to human life. They can even substitute metals in terms of use and applications because of their flexibility, toughness, excellent barrier and physical properties and ease of fabrication. ${ }^{1-4}$ Plastics can be broadly classified into commodity plastics and engineering plastics. Commodity plastics such as Low-density polyethylene (LDPE), high-density polyethylene (HDPE), polypropylene (PP), Polyvinyl chloride (PVC), Polystyrene (PS) and polyethylene terephthalate (PET) account for approximately 90 per cent of the global plastic demand. ${ }^{5}$ Plastic bags, straws, water bottles, coffee cups, packaging materials and many other products are manufactured using these commodity plastics and are considered as disposable plastics or single use plastics. They are used only once and are normally thrown in the trash or recycled. Littering of these products are creating a serious threat to the environment in terms of pollution; be it water, soil or air. A recent report indicate that almost $60 \%$ of these single use plastics are discarded and accumulated in landfills or end up as litter in the environment. ${ }^{6}$ Currently most of the countries are trying to reduce the consumption of single use plastics so that the amount of waste could be limited.

The accumulation of plastics in the environment is a matter of great concern leading to long-term environment, economic and waste management problems. ${ }^{7-10}$ Degradation of waste plastics through various means becomes one of the alternatives to deal with such problems. ${ }^{11}$ A wide variety of synthetic polymers absorb solar ultraviolet (UV) radiation and undergoes photolytic, photo-oxidative, and thermo-oxidative reactions that result in the degradation of these materials. ${ }^{12,13}$ The chances of plastic products to undergo solar UV radiation induced degradation/ ozoneinduced degradation have been increased by addition of some additives in these polymers. ${ }^{14,15}$ Besides these degradations, biodegradation offers another most efficient and attractive route to environmental waste management. Various biodegradable materials are blended with commodity plastics as an attempt to induce biodegradability to these plastics. Starch, ${ }^{16}$ poly lactic acid (PLA) ${ }^{17,18}$ and polycaprolactone (PCL) ${ }^{19}$ are typical examples. On the other hand, many of the products need stability instead of degradation. Therefore, depending upon the end use applications, plastics needs controlled thermal stability. In order to increase the outdoor life of plastics, the development and production of polymers with increased weathering resistance is required. ${ }^{20,21}$

Plastic degradation can be accounted as various types of polymeric degradations (photo-oxidative degradation, thermal degradation, ozone-induced degradation, mechanochemical degradation, catalytic degradation and biodegradation) and all these degradation models undergo

\footnotetext{
a Corresponding Author: Department of Chemical Engineering Technology, PO Box 30436, Yanbu Industrial College, Yanbu Industrial City, 41912, Kingdom of Saudi Arabia. Email: rajank@rcyci.edu.sa
} 
Table 1. Characteristics of the raw PP used for the studies

\begin{tabular}{|l|l|l|}
\hline & A & B \\
\hline Trade Name & Teldene H03BPM & Teldene H11BF \\
\hline Density (ISO 1183) & $0.900 \mathrm{~g} / \mathrm{cm}^{3}$ & $0.900 \mathrm{~g} / \mathrm{cm}^{3}$ \\
\hline Melt flow rate (230 $\left.{ }^{\circ} \mathrm{C} / 2.16 \mathrm{~kg}\right)$ & $3.0 \mathrm{~g} / 10 \mathrm{~min}$ & $11 \mathrm{~g} / 10 \mathrm{~min}$ \\
\hline Tensile modulus (ISO 527-1) & $1450 \mathrm{MPa}$ & $1340 \mathrm{MPa}$ \\
\hline Tensile stress at break (ISO 527-1) & $23.0 \mathrm{MPa}$ & $22.0 \mathrm{MPa}$ \\
\hline Tensile stress at yield (ISO 527-1) & $36.3 \mathrm{MPa}$ & $35 \mathrm{MPa}$ \\
\hline Tensile strain at yield (ISO 527-1) & $>50 \%$ & $>50 \%$ \\
\hline Rockwell Hardness (ASTM D785) & $98(\mathrm{Shore} \mathrm{D)}$ & $90($ Shore D) \\
\hline Heat deflection temperature (ISO 75B-1) & $85^{\circ} \mathrm{C}$ & $94^{\circ} \mathrm{C}$ \\
\hline Vicat softening temperature (ISO 306) & $156^{\circ} \mathrm{C}$ & $150^{\circ} \mathrm{C}$ \\
\hline Haze (ASTM D1003) & $0.7 \%$ & $0.9 \%$ \\
\hline
\end{tabular}

by different mechanisms. ${ }^{22-26}$ Severini et al investigated the environmental degradation of PP films and reported a gradual decrease in mechanical properties ${ }^{27}$ and attributed this reduction due to the $\beta$-scission reaction. The mechanism and kinetics of photooxidation of PP was investigated by Carlsson and co-workers. ${ }^{28,29}$ The degradation behavior of PP films based on seasonal variation during weathering studies is reported by Rajakumar et al. ${ }^{30}$

A clear understanding of the effect of sunlight on the commodity plastics is very much essential to tailor these polymers for various out door applications. In addition to that, this will help the researchers to fine tune the plastic degradation profile in their future attempts towards development of more eco-friendly sustainable packaging materials. In the present investigation, the degradation aspects of two types of single use polypropylene (PP) films were studied under sunlight in Saudi Arabian hot climate (April to September) at Yanbu Industrial City. The effect of direct sunlight and humidity on these polymers were studied based on infra-red spectroscopy, optical microscopy, mechanical and thermal analysis.

\section{MATERIALS AND METHODS}

Two types of polypropylene granules were used for the study and were obtained from NATPET, Saudi Arabia (Teldene H03BPM and Teldene H11BF) and are denoted as samples A and B. The typical properties of these PP granules are given in Table 1.

\section{SAMPLE PREPARATION AND WEATHERING STUDIES UNDER NATURAL CONDITIONS}

The films ( $9 \mathrm{~cm} \times 9 \mathrm{~cm} \times 1 \mathrm{~mm}$ ) were prepared from virgin PP using a modular co-rotating $24 \mathrm{~mm}$ twin screw extruder with an L/D ratio of 25:1 (Haake Rheodrive 16 OS) fitted with a sheet die. The temperature of the extruder from feed zone to die was gradually increased from 140 to $240{ }^{\circ} \mathrm{C}$ with a ten-zone heating profile. The screw speed was fixed at $200 \mathrm{rpm}$. A wooden frame was fabricated to firmly hold the specimens for exposure to sunlight. The set-up is shown in figure 1. The films were taken out every month for morphology and structural analysis. The average atmospheric temperature during the selected period is given in Table 2 . The samples were labelled based on the number of months of exposure. Therefore, 0 means the virgin film, the control sample. The exposed samples were labelled as 1, 2, 3, 4 and so on.

\section{POLARISED OPTICAL MICROSCOPY}

The morphology of the films were observed and recorded using Zeiss AxioCam MRc 5 polarised optical microscope (POM) by keeping the films between two glass slides.

\section{FTIR SPECTROSCOPY}

In order to understand the structural changes of the exposed films with respect to the control samples, Fourier transform infra-red spectroscopy (FTIR) measurements were carried out using IFS 66 V/S (Bruker) Spectrometer with ATR technique with 'Golden Gate' Unit. 32 scans were recorded for each measurement with spectral resolution of $4 \mathrm{~cm}^{-1}$ within the range of 4000 to $400 \mathrm{~cm}^{-1}$.

\section{MECHANICAL PROPERTIES}

Tensile testing was performed using an Instron (3365) universal testing machine fitted with $10 \mathrm{kN}$ load cell at a crosshead speed of $10 \mathrm{~mm} / \mathrm{min}$ as described in ASTM D882.

\section{DIFFERENTIAL SCANNING CALORIMETRY}

Differential scanning calorimetric (DSC) studies were carried out on a Shimadzu 60 DSC at a heating rate of $10^{\circ} \mathrm{C}$ /min from room temperature to $200^{\circ} \mathrm{C}$ with samples of mass approximately equal to $10 \mathrm{mg}$. The samples were first heated to $200^{\circ} \mathrm{C}$ to remove the thermal history and cooled to $30^{\circ} \mathrm{C}$ at a cooling rate of $10^{\circ} \mathrm{C} / \mathrm{min}$. The second heating and first cooling curves were used for analysis. 
Table 2. Climate parameters in Yanbu Industrial City ${ }^{31}$

\begin{tabular}{|l|l|l|l|l|l|}
\hline \multirow{2}{*}{ Month } & \multicolumn{2}{|l|}{$\begin{array}{l}\text { Average Temperature } \\
\left({ }^{\circ} \mathrm{C}\right)\end{array}$} & $\begin{array}{l}\text { Average Humidity } \\
(\%)\end{array}$ & $\begin{array}{l}\text { Average day light } \\
\text { (hours) }\end{array}$ & $\begin{array}{l}\text { Average solar radiation (kW/ } \\
\left.\mathrm{m}^{2}\right)\end{array}$ \\
\cline { 2 - 5 } & High & Low & & 12.7 & 0.9 \\
\hline April & 34.7 & 20.7 & 49 & 13.3 & 1.0 \\
\hline May & 38.2 & 23.8 & 47 & 13.6 & 1.0 \\
\hline June & 40.1 & 25.1 & 50 & 13.5 & 1.1 \\
\hline July & 40.1 & 26.4 & 54 & 12.9 & 1.1 \\
\hline August & 40.4 & 27.3 & 54 & 12.3 & 1.0 \\
\hline September & 39.9 & 26.1 & 55 & & \\
\hline
\end{tabular}

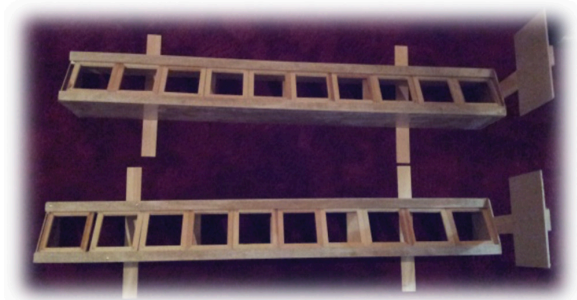

(a)

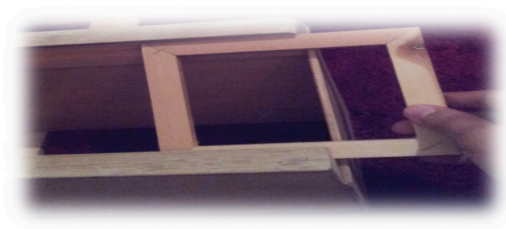

(b)

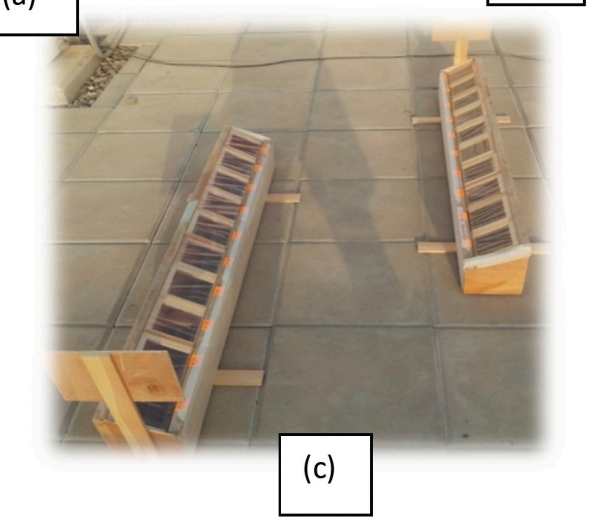

Figure 1. (a) the setup which can hold 6 samples, (b) the sliding unit which can hold one sample and (c) the setup with fixed samples

\section{THERMOGRAVIMETRIC ANALYSIS}

The thermogravimetric analysis was done in a Shimadzu TA60 DTG analyzer under nitrogen atmosphere. Samples of $10 \mathrm{mg}$ were heated from 30 to $700^{\circ} \mathrm{C}$ at a heating rate of $10^{\circ} \mathrm{C} / \mathrm{min}$.

\section{MICROCALORIMETRY MEASUREMENTS}

Small-scale flammability tests were carried out on the Federal Aviation Administration's Pyrolysis Combustion Flow Calorimeter, and samples were tested in triplicate according to ASTM D7309-07. Samples were $7 \mathrm{mg}$ ( $\pm 0.5 \mathrm{mg}$ ) in weight and were obtained from the center of the film without any debris. The heating rate was $60^{\circ} \mathrm{C} / \mathrm{min}$ in an $80 \mathrm{~cm}^{3} / \mathrm{min}$ stream of nitrogen; the maximum pyrolysis temperature was $900^{\circ} \mathrm{C}$. The anaerobic thermal degradation products in the nitrogen gas stream were mixed with a $20 \mathrm{~cm}^{3} / \mathrm{min}$ stream of oxygen prior to entering the combustion furnace at $900^{\circ} \mathrm{C}$. The heat release was determined by oxygen consumption calorimetry. Peak heat release rate (PHRR) data were reproducible within $\pm 0.5 \%$.

\section{CONTACT ANGLE MEASUREMENTS BY GONIOMETRY}

Contact angles were estimated with a goniometer equipped with a special optical system and a camera using a FTA 200 machine. A drop of water $(5 \mu \mathrm{l})$ was placed on a specially prepared plate of substratum and the image was immediately sent via the camera to the computer and imaged using Imaging SCA20 software. Temperature and humidity were constant during the experiment $\left(23^{\circ} \mathrm{C}\right.$ and $68 \%$ respectively). 


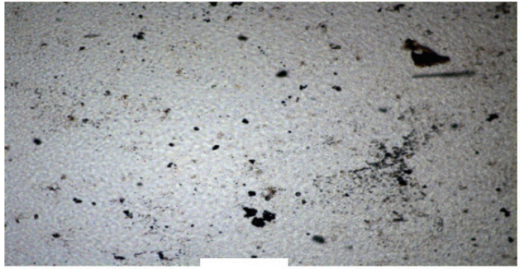

(a)

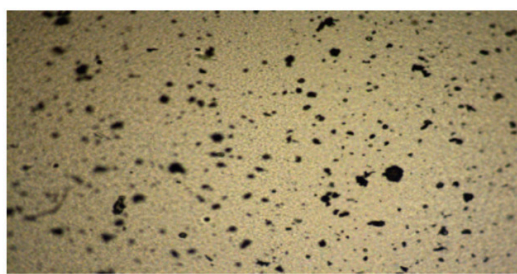

(c)

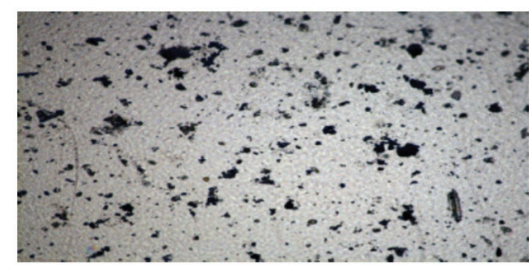

(e)

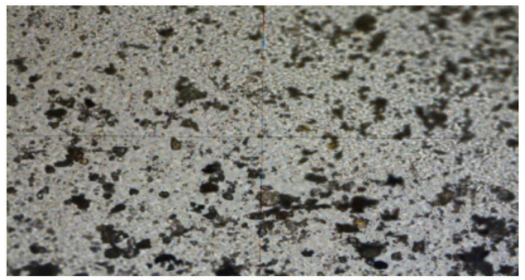

(g)

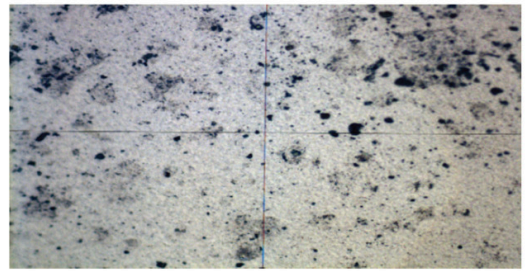

(b)

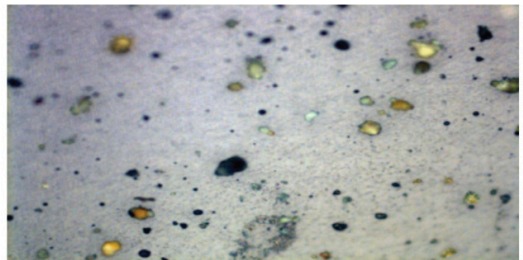

(d)

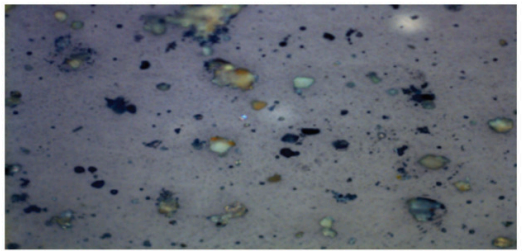

(f)

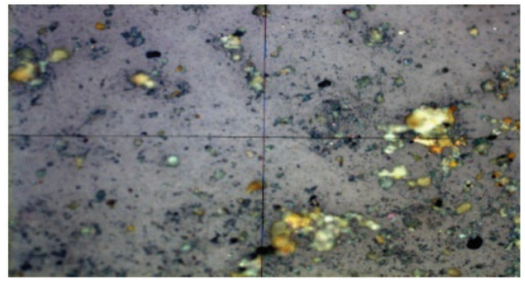

(h

Figure 2. Microscopic images of the films of sample A under natural weathering conditions i) transmission mode: a) after 0 month, c) after 1 month, e) after 3 months and g) after 6 months; ii) reflection mode: b) after 0 month d) after 1 month, f) after 3 months and h) after 6 months

\section{RESULTS AND DISCUSSION}

\section{OPTICAL MICROSCOPY STUDIES}

The samples were kept over the roof top for 6 months. They were allowed to interact with sunlight, sand and wind. The samples were taken out periodically, i.e., every month, and were analyzed using a high-end microscope to understand the changes appearing on the surface. Optical microscopy is considered as a quick technique to follow the changes in the morphology of aged packaging films. ${ }^{32}$ Both sample A and sample B showed similar morphological features under the microscopic examination and hence only the microscopic images of sample A are reported here. The images were obtained in two modes, transmission mode and reflection mode. In the case of transmission mode, the light passes through the film and the surface is shown in the image. The opaque particles were visible there. In the second mode, reflection from the surface is monitored. The particles or debris over the surface can reflect part of the light and this reflection will give clear idea about the surface structure.

Figure 2 shows images of polymer film irradiated with natural weathering sources at different time intervals. The transmitted and reflected images of the virgin polymer film showed smooth surface without any cracks or wrinkles (figure $2 \mathrm{a}$ and $2 \mathrm{~b})$. The images in $\underline{2}$ (c) and (d) were taken after one month of treatment. It is clearly visible that the surface has not changed much and the deposit of debris or particles is very few. It is understandable that being polypropylene there is absolutely no chance of significant changes in one month time.

Fig 2 (e) and (f) shows the transmitted and reflected image of the film after three months of treatment. Compared to the first month the structure is different. The detailed examination of the images shows slight cracks in the film. The debris acts as initiators of the degradation of the films. However, being polyolefin, the extent of degradation is very low. Fig 2 (g) and (h) shows the images after 6 months of weathering. It is seen that the number of dusts and debris are very high compared to the previous months. Also there are more cracks in the film. In conclusion, the microscopic images show us that the microstructure of the surfaces of the films can be studied in detail. The degradation profile of 
Table 3. Tensile properties of the samples

\begin{tabular}{|c|c|c|c|c|}
\hline \multirow{2}{*}{ No. of months } & \multicolumn{2}{|c|}{ Tensile modulus (MPa) } & \multicolumn{2}{c|}{ Tensile strength (MPa) } \\
\cline { 2 - 5 } & $\mathrm{A}$ & $\mathrm{B}$ & $\mathrm{A}$ & $\mathrm{B}$ \\
\hline 0 & $1420 \pm 12$ & $1340 \pm 10$ & $23.0 \pm 0.3$ & $22.0 \pm 0.5$ \\
\hline 1 & $1400 \pm 11$ & $1320 \pm 11$ & $22.4 \pm 0.5$ & $21.6 \pm 0.5$ \\
\hline 2 & $1369 \pm 13$ & $1300 \pm 12$ & $22.0 \pm 0.6$ & $21.2 \pm 0.4$ \\
\hline 3 & $1355 \pm 10$ & $1289 \pm 13$ & $21.2 \pm 0.6$ & $21.0 \pm 0.5$ \\
\hline 4 & $1346 \pm 9$ & $1268 \pm 8$ & $20.6 \pm 0.4$ & $20.6 \pm 0.4$ \\
\hline 5 & $1337 \pm 11$ & $1260 \pm 9$ & $20.0 \pm 0.4$ & $19.2 \pm 0.6$ \\
\hline 6 & $1320 \pm 10$ & $1220 \pm 11$ & $18.9 \pm 0.6$ & $18.4 \pm 0.5$ \\
\hline
\end{tabular}

the films can be correlated with other properties too.

\section{FTIR STUDIES}

FTIR curves show the distribution of the various functional groups in a compound or molecule. Each chemical compound has specific peaks for the functional groups. Therefore, FTIR spectrum is very useful to identify the chemical structure of the material. The figure 3 shows the different chemical groups present in polypropylene film (sample A) and the effect of weathering on it. The curves were re-plotted with an arbitrary y-axis. The structure of PP is very simple and the possibility of different types of vibrations such as symmetric, asymmetric, scissoring and rocking as well as interaction with neighboring atoms are possible. Thus peaks around 2950, 1456, 1377, 887 and $739 \mathrm{~cm}^{-1}$ correspond to these vibrations. ${ }^{33}$ The weathering conditions slightly changed the behavior of the peaks as can be seen in the figure. The intensity of the peak at 1377 was found to increase with respect to time. Also, the presence of a small band of $\mathrm{C}=\mathrm{O}$ functional group (ketones) corresponding to $1735 \mathrm{~cm}^{-1}$ from month 3 onwards indicate that the degradation has started in the film. As the intensity of exposure to sunlight increases, the degradation product formation shifts from acids to esters. ${ }^{34}$ Ketones are one of the main functional groups produced in the degraded polyolefins subjected to photooxidation. ${ }^{30}$

\section{MECHANICAL PROPERTIES}

One of the most important physical properties that will be affected by exposure of plastic films to sunlight is the mechanical properties. Mechanical properties of the films were measured in the tensile mode. Tensile strength and tensile modulus showed a decrease with respect to the natural weathering treatment. The decrease can be attributed to the loss of mass from the films due to the interaction with harsh conditions. The numerical values of the tensile strength and tensile modulus are given in Table 3 . Both films show similar behavior with respect to the tensile properties. The tensile strength values showed a decrease due to the degradation in the sample as the debris initiate cracks in the film. The cracks accelerate the brakeage of the films during the tensile tests easily. The films showed 17 and $16 \%$ reduction in tensile strength during the period of study. The tensile modulus also showed decrease which can be attributed to

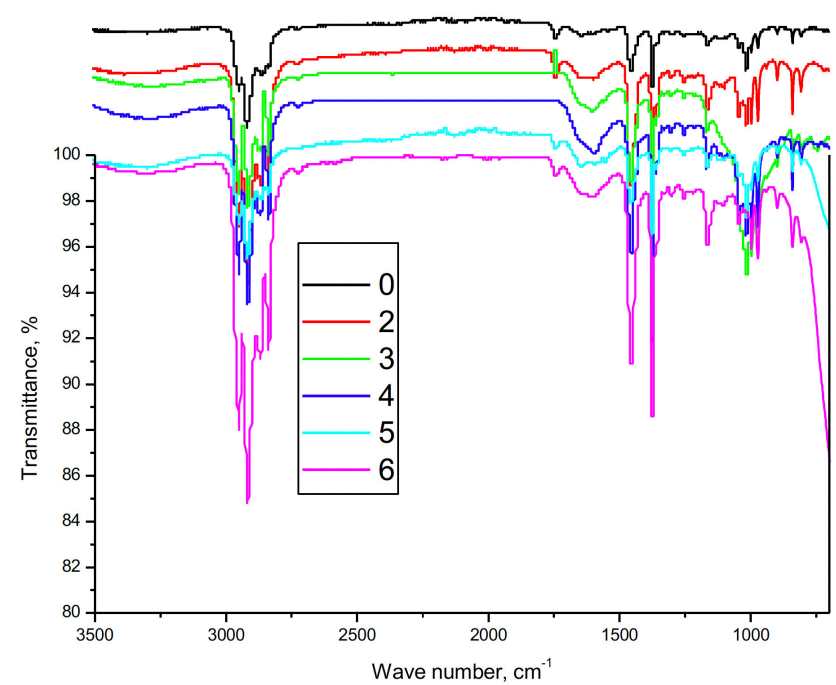

Figure 3. FTIR spectra of films of Sample A

the loss of mass during the weathering study.

\section{DSC MEASUREMENTS}

Figures $\underline{4}$ and $\underline{5}$ show the melting and crystallization curves for the PP films from DSC study. It can be seen from the curves that the melting point of the films decreased upon weathering. The values are given in Table 4. The virgin PP has a melting point of $163^{\circ} \mathrm{C}$ and $169^{\circ} \mathrm{C}$ respectively for the two samples. Upon weathering they sharply decrease to 147 and $149^{\circ} \mathrm{C}$ respectively for two variants of PP. The decrease in melting point may be attributed to the reduction in the molecular weight of the polymer chains due to the random chain scission arising from the exposure to the sunlight and the associated structural changes in the films. ${ }^{35}$ There has been a change in the functional groups as reported in FTIR which corroborates the decrease in melting point.

From figure 5, the crystallization behavior of the composites can be analyzed on weathering of PP samples for 6 months under hot climate. The crystallization temperature for samples are 120 and $125^{\circ} \mathrm{C}$ respectively. Both the samples show a gradual decrease in crystallization temperature on weathering. The decrease in crystallization temperature can be attributed to the increase in crystal defects occur- 
Table 4. Melting and crystallization temperatures of the samples

\begin{tabular}{|c|c|c|c|c|}
\hline \multirow{2}{*}{ No. of months } & \multicolumn{2}{|c|}{ Melting point $\left({ }^{\circ} \mathrm{C}\right)$} & \multicolumn{2}{c|}{ Crystallization temperature $\left({ }^{\circ} \mathrm{C}\right)$} \\
\cline { 2 - 5 } & A & B & A & B \\
\hline 0 & 163 & 169 & 120 & 125 \\
\hline 2 & 157 & 162 & 119 & 123 \\
\hline 4 & 153 & 154 & 117 & 121 \\
\hline 6 & 149 & 147 & 115 & 119 \\
\hline
\end{tabular}

ring with degradation of the samples. The degraded chains along with oxygenated groups, double bonds, chain ends and branch sites lead to smaller crystals with more imperfections. ${ }^{36}$ In order to get the correct data, both the melting and crystallization tests were conducted thrice for each sample and the average values are reported in Table 4.

\section{THERMOGRAVIMETRIC ANALYSIS}

The thermogravimetric analysis of the PP films was carried out to understand the effect of weathering conditions on the thermal degradation. Figure 6 shows the thermograms of the two types PP films and Table 5 summarizes the onset of degradation and maximum degradation temperature data obtained from these curves. The onset of degradation for PP films is around 426 and $441^{\circ} \mathrm{C}$ respectively for samples $\mathrm{A}$ and $\mathrm{B}$. The onset of degradation showed an earlier initiation for both type of films. As can be seen from the Table, the onset of degradation started from 341 and $424^{\circ} \mathrm{C}$ respectively after 6 months of treatment under the hot climatic conditions. This decrease in the value can be ascribed to the degradation of the sample due to the UV irradiation as well as deterioration of the sample surface due to the harsh conditions.

\section{MICROCALORIMETRIC STUDIES}

The flammability of the samples was measured using a pyrolysis combustion flow calorimeter, also known as a microscale combustion calorimeter (MCC). Table 6 shows the different parameters obtained by the testing such as peak heat release rate (PHRR), total heat release (THR), and heat release capacity (HRC) for both the samples. The HRC generally accounts for the fire hazard of a particular material and it is given as the ratio of maximum heat release to a particular heating rate. It is evident from the table that the HRC values decrease with respect to time of weathering. The loss of mass of the films due to the weathering agents and the deposition of debris on the surface of the films might have caused the decrease in HRC values. The changes in the surface features can cause restricted heat conduction throughout the film. Sample A and B shows decrease in HRC by 6 and $12 \%$ respectively after 6 months of interaction with weathering conditions on rooftops.

Another important parameter to understand the flammability is PHRR. Both samples show decrease in PHRR with respect to time. The fire safety of the material is analyzed based on the trend in PHRR and it will give an idea at which point the fire will propagate further or the ignition
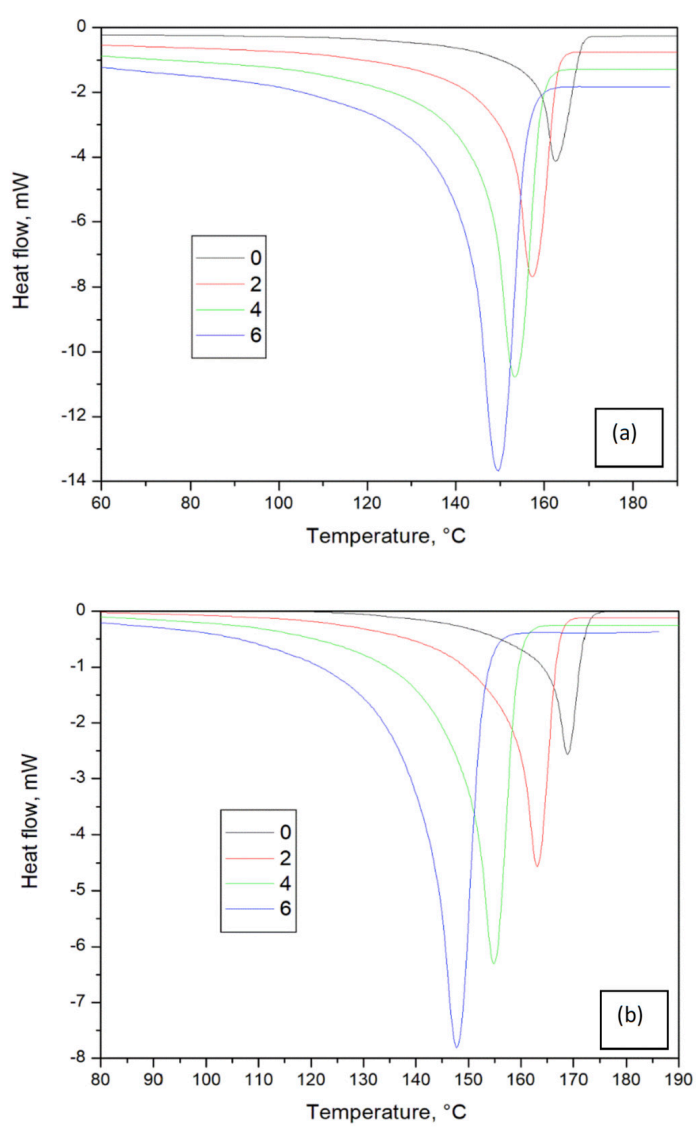

Figure 4. Melting peaks of PP films (a) sample A and (b) sample B

of adjacent objects will start. Both samples show a decrease in the range of $8-10 \%$ of PHRR after exposure to 6 months of weathering conditions. Total heat release from the tested samples is also shown in Table 6. Sample B shows more decrease compared to sample A which means that the effect of weathering conditions is more effective in it. The flammability data of the two types of PP samples can be attributed to the prevention of supply of oxygen from the surface due to deposition of debris and changes in surface features. It also corroborates the data obtained in TGA analysis as the maximum degradation temperature and onset of degradation showed a decrease. 
Table 5. TGA data of the samples

\begin{tabular}{|c|c|c|c|c|}
\hline \multirow{2}{*}{ No. of months } & \multicolumn{2}{|c|}{ Onset of degradation $\left({ }^{\circ} \mathrm{C}\right)$} & \multicolumn{2}{c|}{ Maximum degradation temperature $\left({ }^{\circ} \mathrm{C}\right)$} \\
\cline { 2 - 5 } & A & B & A & 478 \\
\hline 0 & 426 & 441 & 467 & 471 \\
\hline 2 & 405 & 429 & 463 & 457 \\
\hline 4 & 402 & 428 & 458 & 450 \\
\hline 5 & 373 & 425 & 443 & 447 \\
\hline 6 & 341 & 424 & 422 & B \\
\hline
\end{tabular}

Table 6. The effect on peak heat release rate (PHRR), total heat release (THR) and heat release capacity (HRC) of samples

\begin{tabular}{|c|c|c|c|c|c|c|}
\hline \multirow{2}{*}{ No. of months } & \multicolumn{3}{|c|}{ A } & \multicolumn{3}{c|}{ B } \\
\hline & PHRR (W/g) & THR (kJ/g) & HRC (J/gK) & PHRR (W/g) & THR (kJ/g) & HRC (J/gK) \\
\hline 0 & $1050 \pm 8$ & $40.3 \pm 0.22$ & $1032 \pm 7$ & $1035 \pm 8$ & $40.4 \pm 0.22$ & $1036 \pm 7$ \\
\hline 2 & $1019 \pm 6$ & $39.3 \pm 0.21$ & $1024 \pm 6$ & $1029 \pm 6$ & $40.3 \pm 0.21$ & $1029 \pm 6$ \\
\hline 4 & $1006 \pm 5$ & $38.9 \pm 0.18$ & $1012 \pm 4$ & $1011 \pm 5$ & $37.9 \pm 0.18$ & $978 \pm 4$ \\
\hline 5 & $991 \pm 6$ & $37.1 \pm 0.21$ & $989 \pm 5$ & $989 \pm 6$ & $35.1 \pm 0.21$ & $934 \pm 5$ \\
\hline 6 & $971 \pm 4$ & $35.9 \pm 0.17$ & $976 \pm 5$ & $945 \pm 4$ & $32.9 \pm 0.17$ & $906 \pm 5$ \\
\hline
\end{tabular}

\section{CONTACT ANGLE STUDIES}

Water contact angle reflect the hydrophilic/hydrophobic nature of the material. PP is devoid of any hydrophilic groups on the surface and both the films show hydrophobic nature as both of them have high contact angle values (Table 7). However, the contact angle values show a marginal decrease with weathering conditions for six months. Contact angle showed a decrease from 85 to 70 for sample A and 78 to 62 for sample B respectively after 6 months. Roughly 18 and $20 \%$ decrease in contact angles can be assumed due to the changes in the surface features. Hydrophobic PP in contact with air can lead to reorientation of the polar groups, arising out of the degradation of the polymer chains, toward the bulk material and can lead to a reduction in the contact angles. ${ }^{37}$ The deposition of sand and other particles and increase in surface roughness might also contribute to decrease in contact angle and thereby increase the hydrophilicity of the samples even though to a marginal extent.

\section{CONCLUSION}

Polypropylene packaging films of two different grades were investigated to understand the effect of Saudi Arabian climatic conditions on the environmental degradation. The sunlight exposure was carried out using specially designed sample holders. The samples were analyzed at regular intervals with respect to changes in structural, mechanical, thermal and flammability properties. The FTIR spectra of the samples revealed the degradation of the polymer chains and indicated the presence of ketone groups on the polymer surface. The thermal analysis showed that the maximum
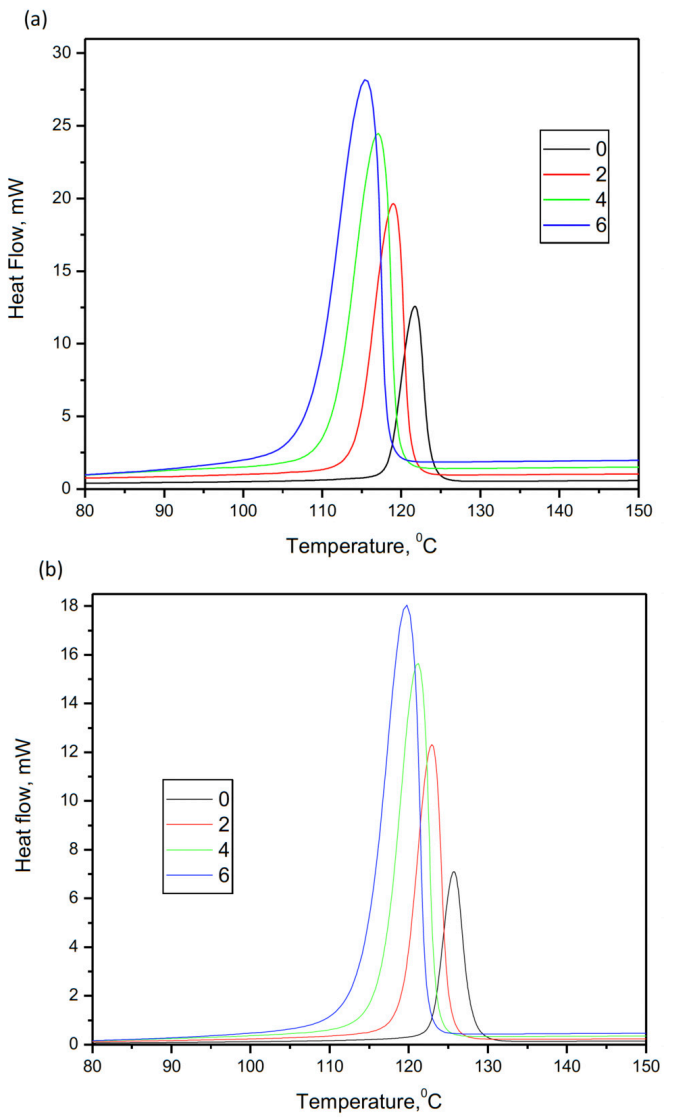

Figure 5. Crystallization peaks of PP films (a) sample $A$ and (b) sample $B$

degradation temperature decreased to appreciable amount 
Table 7. Contact angle values of samples

\begin{tabular}{|c|c|c|}
\hline \multirow{2}{*}{ No. of months } & \multicolumn{2}{|c|}{ Contact angle } \\
\cline { 2 - 3 } & $\mathrm{A}$ & $\mathrm{B}$ \\
\hline 0 & $85 \pm 1$ & $78 \pm 0.8$ \\
\hline 1 & $83 \pm 0.8$ & $75 \pm 0.9$ \\
\hline 2 & $80 \pm 1$ & $70 \pm 0.8$ \\
\hline 3 & $76 \pm 1$ & $60 \pm 0.7$ \\
\hline 4 & $74 \pm 0.9$ & $64 \pm 0.9$ \\
\hline 5 & $71 \pm 0.7$ & $62 \pm 0.8$ \\
\hline 6 & $70 \pm 0.7$ & \multicolumn{2}{|c|}{} \\
\hline
\end{tabular}

during the six-month window. The contact angle measurements also showed almost $20 \%$ decrease which is noteworthy in the case of polymers like polypropylene. The flammability parameters decreased for both the samples. From these results it is certain that the natural degradation of polypropylene films under direct sunlight exposure and humidity will take very long time and within a short span of time it is very difficult to achieve significant changes in the degradation of single use disposable plastics. The exposed PP films still have the mechanical properties recommended for the use of commercial packaging films. Moreover, other investigations are necessary to understand the detailed degradation mechanism. (a)

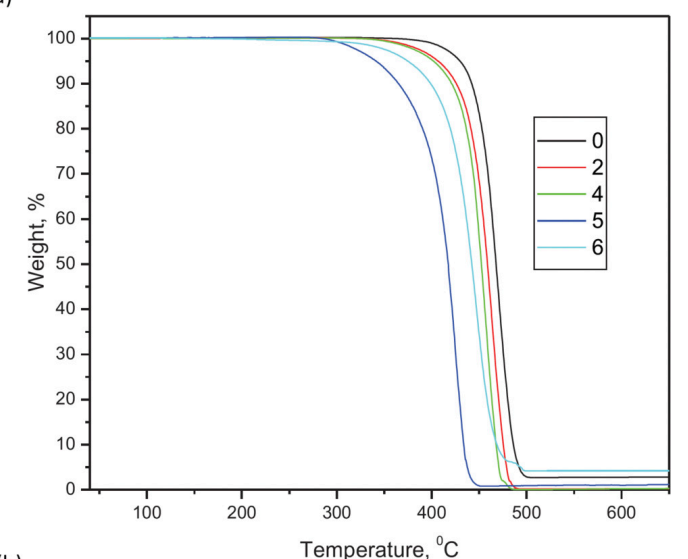

(b)

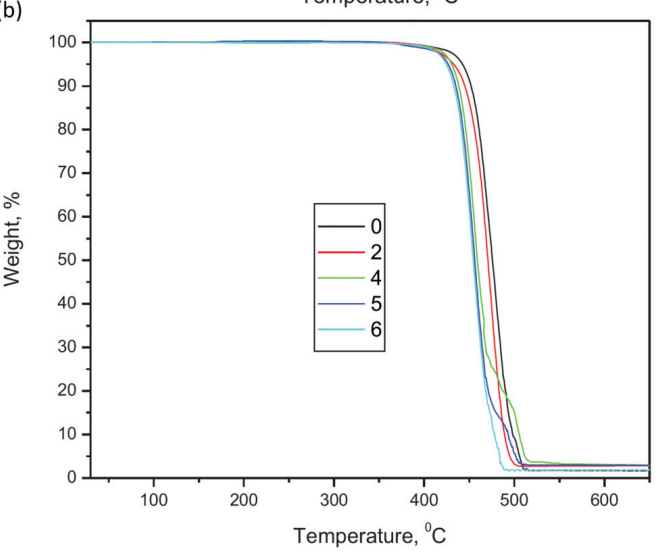

Figure 6. Thermograms of PP films (a) sample A and (b) sample B

Submitted: September 18, $2021+03$, Accepted: October 18, $2021+03$ 


\section{REFERENCES}

1. Meenakshi P, Noorjahan SE, Rajini R, Venkateswarlu U, Rose C, Sastry TP. Mechanical and microstructure studies on the modification of CA film by blending with PS. Bull Mater Sci. 2002;25(1):25-29. doi:10.1007/BF02704590

2. McKeen LW. Permeability Properties of Plastics and Elastomers. William Andrew; 2016.

3. Gruenwald G. Thermoforming: A Plastics Processing Guide. Routledge; 2018.

4. Osswald TA, Baur E, Rudolph N. Plastics Handbook: The Resource for Plastics Engineers. Carl Hanser Verlag GmbH Co KG; 2019.

5. Andrady AL, Neal MA. Applications and societal benefits of plastics. Philos Trans $R$ Soc B Biol Sci. 2009;364(1526):1977-1984.

6. Rajan KP, Thomas SP, Gopanna A, Chavali M. Polyhydroxybutyrate (PHB): A standout biopolymer for environmental sustainability. Handbook of Ecomaterials. 2019;4. doi:10.1007/978-3-319-6825 $\underline{5-692}$

7. Bernardo CA, Simões CL, Pinto LMC. Environmental and economic life cycle analysis of plastic waste management options. A review. In: AIP Conference Proceedings. AIP Publishing; 2016:140001.

8. ten Brink P, Schweitzer JP, Watkins E, et al. Circular economy measures to keep plastics and their value in the economy, avoid waste and reduce marine litter. Economics Discussion Papers. 2018.

9. Kulkarni VS, Shastri Y. Economic Analysis and Life Cycle Assessment of Pyrolysis of Plastic Waste in Mumbai, India. In: Sustainable Waste Management: Policies and Case Studies. Springer; 2020:453-463.

10. Fast J, Haughn J, Miller H, Jiang Z. The Price of Plastic: An Analysis of the Environmental and Economic Impacts and Social Perceptions of SingleUse Plastic Containers at Dalhousie University. 2019.

11. Degnan T, Shinde SL. Waste-plastic processing provides global challenges and opportunities. MRS Bull. 2019;44(6):436-437.

12. Hamid SH. Handbook of Polymer Degradation. CRC Press; 2000.
13. Patel JB, Tiwana P, Seidler N, et al. The Effect of Ultraviolet Radiation on Organic Photovoltaic Materials and Devices. ACS Appl Mater Interfaces. 2019.

14. Luengo C, Allen NS, Edge M, et al. Photooxidative degradation mechanisms in styrene-ethylene-butadiene-styrene (SEBS) triblock copolymer. Polym Degrad Stab. 2006;91(4):947-956.

15. Kumar HD, Häder DP. Solar ultraviolet radiation. In: Global Aquatic and Atmospheric Environment. Springer; 1999:341-376.

16. do Val Siqueira L, Arias CILF, Maniglia BC, Tadini CC. Starch-based biodegradable plastics: Methods of production, challenges and future perspectives. Curr Opin Food Sci. 2020.

17. Rajan KP, Al-Ghamdi A, Thomas SP, Gopanna A, Chavali M. Dielectric analysis of polypropylene (PP) and polylactic acid (PLA) blends reinforced with halloysite nanotubes. J Thermoplast Compos Mater. 2018;31(8):1042-1053. doi:10.1177/089270571773459 5

18. Rajan KP, Thomas SP, Gopanna A, Al-Ghamdi A, Chavali M. Rheology, mechanical properties and thermal degradation kinetics of polypropylene (PP) and polylactic acid (PLA) blends. Mater Res Express. 2018;5(8). doi:10.1088/2053-1591/aad1d3

19. Arcana IM, Bundjali B, Yudistira I, Jariah B, Sukria L. Study on properties of polymer blends from polypropylene with polycaprolactone and their biodegradability. Polym J. 2007;39(12):1337-1344.

20. Lahimer MC, Ayed N, Horriche J, Belgaied S. Characterization of plastic packaging additives: food contact, stability and toxicity. Arab J Chem. 2017;10:S1938-S1954.

21. Almeida D, Marques M de F. Thermal and catalytic pyrolysis of plastic waste. Polímeros. 2016;26(1):44-51.

22. Wool RP. The science and engineering of polymer composite degradation. In: Degradable Polymers. Springer; 1995:138-152.

23. Jenkins S, i Quer AM, Fonseca C, Varrone C. Microbial Degradation of Plastics: New Plastic Degraders, Mixed Cultures and Engineering Strategies. Soil Microenviron Bioremediation Polym Prod. 2019:213-238. 
24. Ahmed T, Shahid M, Azeem F, et al.

Biodegradation of plastics: current scenario and future prospects for environmental safety. Environ Sci Pollut Res. 2018;25(8):7287-7298.

25. Haider TP, Völker C, Kramm J, Landfester K, Wurm FR. Plastics of the future? The impact of biodegradable polymers on the environment and on society. Angew Chemie Int Ed. 2019;58(1):50-62.

26. Salomez M, George M, Fabre P, et al. A comparative study of degradation mechanisms of PBSA and PHBV under laboratory-scale composting conditions. Polym Degrad Stab. 2019.

27. Severini F, Gallo R, Ipsale S. Environmental degradation of polypropylene. Polym Degrad Stab. 1988;22(2):185-194.

28. Aspler J, Carlsson DJ, Wiles DM. Initiation of polypropylene photooxidation. 1. Polynuclear aromatic compounds. Macromolecules. 1976;9(5):691-695.

29. Carlsson DJ, Garton A, Wiles DM. Initiation of polypropylene photooxidation. 2. Potential processes and their relevance to stability. Macromolecules. 1976;9(5):695-701.

30. Rajakumar K, Sarasvathy V, Chelvan AT, Chitra R, Vijayakumar CT. Natural weathering studies of polypropylene. J Polym Environ. 2009;17(3):191-202.
31. Climate and Average Weather Year Round in Yanbu. https://weatherspark.com/y/100680/AverageWeather-in-Yanbu-Saudi-Arabia-Year-Round. Accessed September 14, 2021.

32. Rosa DS, Angelini JMG, Agnelli JAM, Mei LHI. The use of optical microscopy to follow the degradation of isotactic polypropylene (iPP) subjected to natural and accelerated ageing. Polym Test. 2005;24(8):1022-1026.

33. Rajan KP, Gopanna A, Abdelghani EAM, Thomas SP. Halloysite nanotubes (HNT) as reinforcement for compatibilized blends of polypropylene (PP) and polylactic acid (PLA). J Polym Res. 2021;28(10):1-15.

34. Yang X, Ding X. Prediction of outdoor weathering performance of polypropylene filaments by accelerated weathering tests. Geotext Geomembranes. 2006;24(2):103-109.

35. Arráez FJ, Arnal ML, Müller AJ. Thermal and UV degradation of polypropylene with pro - oxidant. Abiotic characterization. J Appl Polym Sci. 2018;135(14):46088.

36. Ojeda T, Freitas A, Birck K, et al. Degradability of linear polyolefins under natural weathering. Polym Degrad Stab. 2011;96(4):703-707.

37. Julienne F, Lagarde F, Delorme N. Influence of the crystalline structure on the fragmentation of weathered polyolefines. Polym Degrad Stab. 2019;170:109012. 